\title{
Optimised paediatric antiretroviral treatment to achieve the 95-95-95 goals
}

\begin{tabular}{|c|c|}
\hline \multicolumn{2}{|c|}{$\begin{array}{l}\text { Authors: } \\
\text { Moherndran Archary }{ }^{1,2} \text { (D) } \\
\text { Riana van Zyl }{ }^{3} \text { (D) } \\
\text { Nosisa Sipambo }{ }^{4} \text { (D) } \\
\text { Gillian Sorour }{ }^{4} \text { (D) }\end{array}$} \\
\hline \multicolumn{2}{|c|}{$\begin{array}{l}\text { Affiliations: } \\
{ }^{1} \text { Department of Paediatrics } \\
\text { and Child Health, College of } \\
\text { Health Sciences, University } \\
\text { of KwaZulu-Natal, Durban, } \\
\text { South Africa }\end{array}$} \\
\hline \multicolumn{2}{|c|}{$\begin{array}{l}{ }^{2} \text { Department of Paediatrics, } \\
\text { King Edward VIII Hospital, } \\
\text { Durban, South Africa }\end{array}$} \\
\hline \multicolumn{2}{|c|}{$\begin{array}{l}{ }^{3} \text { Department of Paediatrics } \\
\text { and Child Health, University } \\
\text { of the Free State, } \\
\text { Bloemfontein, South Africa }\end{array}$} \\
\hline \multicolumn{2}{|c|}{$\begin{array}{l}{ }^{4} \text { Department of Paediatrics } \\
\text { and Child Health, University } \\
\text { of the Witwatersrand, } \\
\text { Johannesburg, South Africa }\end{array}$} \\
\hline \multicolumn{2}{|c|}{$\begin{array}{l}\text { Corresponding author: } \\
\text { Moherndran Archary, } \\
\text { Archary@ukzn.ac.za }\end{array}$} \\
\hline \multicolumn{2}{|c|}{$\begin{array}{l}\text { Received: } 21 \text { June } 2021 \\
\text { Accepted: } 14 \text { July } 2021 \\
\text { Published: } 01 \text { Sept. } 2021\end{array}$} \\
\hline \multicolumn{2}{|c|}{$\begin{array}{l}\text { How to cite this article: } \\
\text { Archary M, van Zyl R, } \\
\text { Sipambo N, Sorour G. } \\
\text { Optimised paediatric } \\
\text { antiretroviral treatment to } \\
\text { achieve the } 95-95-95 \text { goals. } \\
\text { S Afr J HIV Med. } 2021 ; 22(1) \text {, } \\
\text { a1278. https://doi. } \\
\text { org/10.4102/sajhivmed. } \\
\text { v22i1.1278 }\end{array}$} \\
\hline \multicolumn{2}{|c|}{$\begin{array}{l}\text { Copyright: } \\
\text { (C) 2021. The Authors } \\
\text { Licensee: AOSIS. This } \\
\text { is licensed under the } \\
\text { Creative Commons } \\
\text { Attribution License. }\end{array}$} \\
\hline \multicolumn{2}{|l|}{ Read online: } \\
\hline aryas & $\begin{array}{l}\text { Scan this QR } \\
\text { code with your } \\
\text { smart phone or } \\
\text { mobile device } \\
\text { to read online. }\end{array}$ \\
\hline
\end{tabular}

While the progress towards reaching the UNAIDS 95-95-95 targets in South African adults seems promising, the progress in the paediatric population is lagging far behind; only $79 \%$ percent of children living with HIV know their status. Of these, only $47 \%$ are on treatment, and a mere $34 \%$ of those are virally suppressed. Thus, virological suppression has been attained in only $13 \%$ of children living with HIV in South Africa. Multiple factors contribute to the high treatment failure rate, one of them being a lack of paediatric-friendly antiretroviral treatment (ART) formulations. For example, the Lopinavir/ritonavir syrup, which is the current mainstay of ART for young children, has an extremely unpleasant taste, contributing to the poor tolerability and lack of adherence by children using the formulation. Furthermore, the lack of appropriate formulations limits the optimisation of regimens, especially for young children and those who cannot swallow tablets. Switching from syrups to dispersible tablets will improve ease of administration and adherence and result in cost-saving. Despite the approval of simplified paediatric-friendly formulations internationally, including other sub-Saharan African countries, unnecessary delays are experienced in South Africa. Clinician groups and community organisations must speak up and demand that approvals be expedited to ensure the delivery of life-changing and life-saving formulations to our patients as a matter of urgency.

Keywords: paediatric; HIV/AIDS; ART; 95-95-95 goals; PMTCT.

According to the latest global Joint United Nations Programme on HIV and AIDS (UNAIDS) estimates, 1.8 million children live with HIV worldwide, with 150000 new infections in children aged 0-14 years contributing to $9 \%$ of the overall new infections in 2019. Of these new infections, $84 \%$ occurred in sub-Saharan Africa, with around 95000 HIV-related deaths in children reported in 2019. ${ }^{1}$ While South Africa's prevention of mother-to-child transmission programme has been successful in decreasing the rate of vertical transmission of HIV to 3\% (from 16\% in 2010), paediatric HIV treatment programmes have not been as successful. ${ }^{2}$

In 2019, HIV-related deaths in South African children declined to 4100, and the number of children living with HIV remained more or less stable at $340000 .{ }^{1}$ As part of working towards ending the HIV pandemic by 2030, attaining and maintaining virological suppression is critical. The current South African statistics in the overall population in terms of the UNAIDS 95-95-95 targets (diagnosis of $95 \%$ of all people living with HIV, achieving 95\% on antiretroviral treatment [ART] among those diagnosed and 95\% virally suppressed among those being treated) are 92-75-92. ${ }^{1}$ In the paediatric population, however, the progress towards meeting the treatment cascade goals is lagging far behind. Only 79\% of children living with HIV know their status. Of these, only $47 \%$ are on treatment, and a mere $34 \%$ of those on treatment are virally suppressed. ${ }^{1}$

Treatment failure is multifactorial, but suboptimal adherence remains the most significant contributing factor. One of the reasons for non-adherence is the difficulty in obtaining treatment. The barriers to accessing treatment include physical challenges such as getting to clinics in remote areas, drug stock-outs and, recently, interrupted clinical services resulting from coronavirus disease 2019 (COVID-19) restrictions. Although the effect of lockdown had a more significant impact on HIV testing and the initiation of ART, the provision of ART was also affected. ${ }^{3}$ Disruptions to HIV programmes during the COVID-19 pandemic will have the most significant impact on HIV-related deaths. Based on modelling studies, the interruption of ART for 6 months in 50\% of patients on ART will result in over 296000 estimated deaths in sub-Saharan Africa annually. ${ }^{4}$

In the paediatric population, adherence is dependent on the motivation and commitment of the parent or caregiver. A lack of appropriate paediatric ART formulations adds to the burden of giving treatment to a child regularly enough to maintain high levels of adherence and obtain viral suppression. The classic 'culprit' is lopinavir/ritonavir (LPV/r) syrup: toddlers often refuse to 
take the treatment or vomit after the parent or caregiver administers the syrup because of the extremely unpleasant taste. In addition, the lack of fixed-dose combinations (FDC) for children results in complicated dosing regimens that negatively affect long-term adherence and retention in care.

\section{Supporting the move to simplified paediatric-friendly formulations}

The shift away from multiple syrup formulations for children unable to swallow tablets, previously the mainstay of the paediatric HIV treatment regimens in South Africa, has been delayed compared to other sub-Saharan African countries. This has been because of the painstakingly slow regulatory approval of generic FDC formulations designed for children. For example, the United States Food and Drug Administration (USFDA) approved the generic FDC of abacavir (ABC) and lamivudine (3TC) (120/60 mg) in 2014 (see Figure 1)..$^{5}$ The South African product submission to the South African Health Products Regulatory Authority (SAHPRA), then called the Medicines Control Council, only followed in 2016. Approval, however, only occurred in 2021, 7 years later.

The impact of optimised paediatric formulations cannot be overemphasised. For example, an $11 \mathrm{~kg}$ infant on $\mathrm{ABC}$ and 3TC will require a $6 \mathrm{~mL}$ twice-daily dose of each syrup, or $24 \mathrm{~mL}$ per day, and a total monthly supply of $672 \mathrm{~mL}$, compared to a child who is switched to an FDC of ABC/3TC $(120 / 60 \mathrm{mg})$ dispersible tablet (DT). Switching to the FDC $\mathrm{ABC} / 3 \mathrm{TC}$ requires two tablets daily, or a bottle of 56 pills per month. ${ }^{7}$ These changes impact the patient and caregiver acceptability and adherence as well as the health system costs, including cost savings on syringes and a decrease in the required storage space.

\section{Abacavir/lamivudine fixed-dose combination formulations}

The FDC of ABC/3TC (600/300 mg) was registered for use in South Africa from 2012 and was included in the paediatric and adolescent dosing guidelines soon afterwards, facilitating a once-daily nucleoside/nucleotide reverse transcriptase inhibitor (NRTI) backbone in children above $25 \mathrm{~kg} .{ }^{8}$ This film-coated tablet should be swallowed whole and not cut or crushed, preventing the use of the formulation in younger children.

The new dispersible scored ABC/3TC FDC (120/60 mg) allows for flexible dosing and administration. The formulation can be dissolved in liquid and administered, chewed or swallowed whole, allowing the use of the formulation from young infants to older children. The dose proportions align with the World Health Organization (WHO) dosage recommendations developed to facilitate once-daily dosing of the NRTI backbone in children over 4 weeks of age and weighing $3 \mathrm{~kg}$. The scored DT allows dosing in increments of $60 / 30 \mathrm{mg}$, which, when cut in half, allows for dosing across a wide weight range from $3 \mathrm{~kg}$ to $25 \mathrm{~kg}$. In addition, the child-friendly flavouring of the formulation adds to the appeal. In South Africa, two generic manufacturers have made this FDC available to patients in the public sector. ${ }^{7}$

\section{Dolutegravir}

The basis for introducing integrase inhibitors into the adult guidelines was the higher genetic barrier to resistance, improved side-effect profile and viral suppression rate associated with dolutegravir (DTG). While evidence for a potential association with neural-tube defects (NTDs) and increased weight gain has slowed down the introduction of DTG, especially in women of child-bearing potential, the opening into the paediatric population has been delayed by

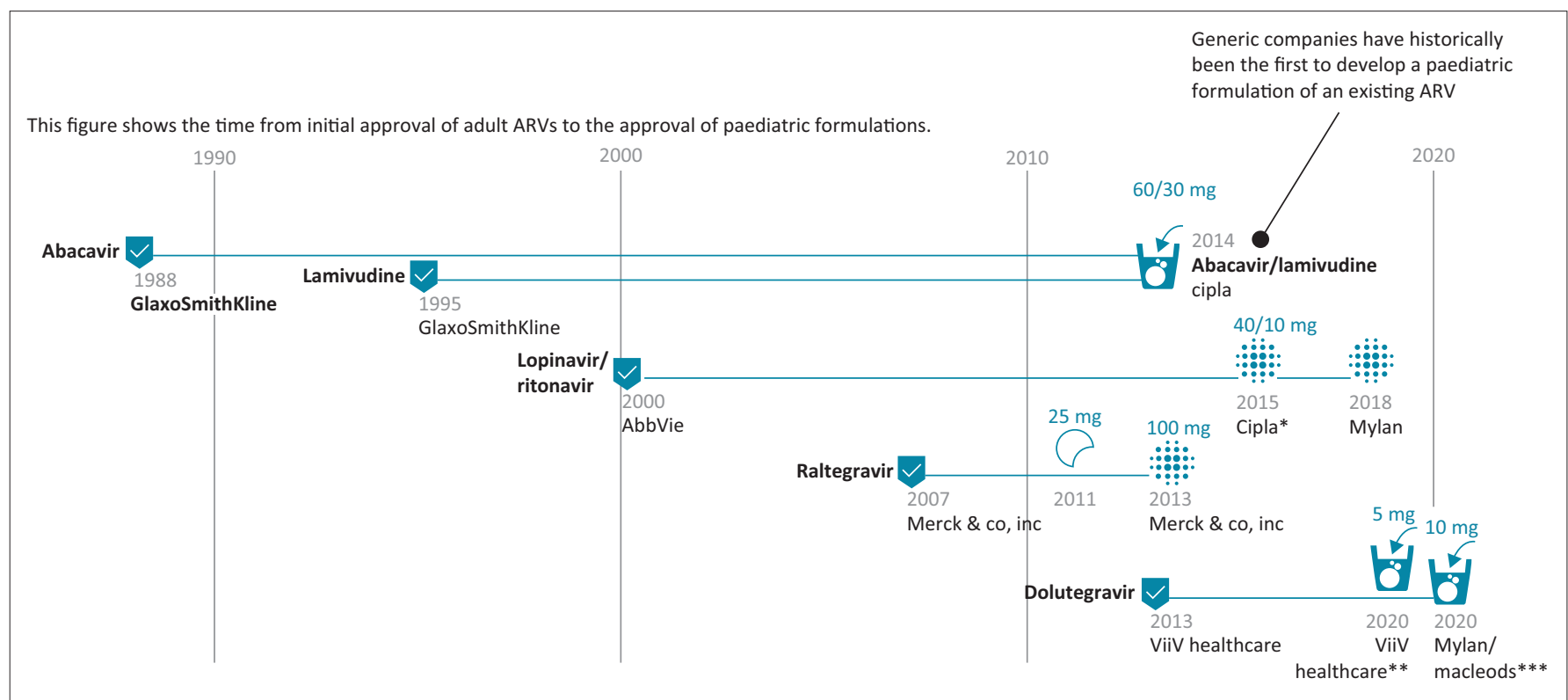

Source: Access to Medicine Foundation. Ending the burden of HIV, malaria and TB in children: Children and the 'big three' epidemics: Despite significant advances in HIV, many children remain at risk, June 2020 [homepage on the Internet]. [cited 2021 June 17]. Available from: https://accesstomedicinefoundation.org/publications/ending-the-burden-of-hiv-malaria-and-tb-in-children. ${ }^{6}$ ARV, antiretroviral.

FIGURE 1: Timelines for paediatric antiretroviral approvals are shortening, but unnecessary delays remain. 
the lack of appropriate formulations. The inclusion of adolescents early into studies such as IMPAACT P1093,10 has allowed their concurrent access, if weighing over $30 \mathrm{~kg}$, to the $50 \mathrm{mg}$ formulation as per the adult formulations in the national guidelines. ${ }^{8}$

The initial registration trial for DTG included $35 \mathrm{mg}$ and $25 \mathrm{mg}$ doses for children weighing $20 \mathrm{~kg}-30 \mathrm{~kg}$ and $15 \mathrm{~kg}-20 \mathrm{~kg}$, respectively, requiring two additional formulations of a $25 \mathrm{mg}$ and $10 \mathrm{mg}$ tablet. Further pharmacokinetic evaluation conducted as a substudy of the Odyssey trial evaluated the use of the $50 \mathrm{mg}$ tablet in children between $20 \mathrm{~kg}$ and $30 \mathrm{~kg}$. ${ }^{11}$ Acceptable pharmacokinetics and side-effect profile supported the USFDA registration of DTG $50 \mathrm{mg}$ daily in children from $20 \mathrm{~kg}$. In addition, the new dosage recommendation was added to the WHO and several national guidelines, including the South African national ART guidelines. ${ }^{8}$

To dose children weighing below $20 \mathrm{~kg}$, a $5 \mathrm{mg}$ dispersible tablet of DTG (DTG DT) was developed by the originator, ViiV. Pharmacokinetic evaluation as part of the P1093 and Odyssey trials again supported the registration of the new formulation by the USFDA and European Medicines Agency in 2020 starting at 4 weeks of age and $3 \mathrm{~kg}$ in weight. ${ }^{12}$ In addition, as part of ViiV's commitment to providing early access to DTG in low- and middle-income countries (LMICs), a sharing of the technical specifications with generic manufacturers has allowed the development of a scored 10 mg DTG DT. ${ }^{13}$ This has allowed DTG to be the first-line ART of choice across the age spectrum from 4 weeks of age in the new consolidated WHO guidelines. Registration of this new dispersible formulation by SAHPRA is eagerly awaited and will allow inclusion in the South African guidelines. The approval of DTG DT will facilitate the move away from using LPV/r syrup formulations and their associated problems.

At a recent conference presentation of the results of the Odyssey trial, there was no significant difference in weight gain in participants on a DTG versus non-DTG-containing regimen. ${ }^{14}$ In addition, the frequency of metabolic adverse events was lower in the DTG arm. These findings are reassuring and further support the use of DTG-based regimens in children. Furthermore, with an increase in the available cohort data, the association of NTDs and the use of DTG in the first trimester has decreased. The additional data support the use of DTG in women of child-bearing potential and has implications for introducing DTG in adolescent girls.

Tuberculosis is a common coinfection in South Africa, especially in people living with HIV. Co-treatment with rifampicin (Rif)-containing tuberculosis treatment and DTG results in a significant decrease in the DTG plasma concentration. Data in the adult population have supported $50 \mathrm{mg}$ twice daily while on Rif to counteract the increased hepatic metabolism. In addition, a substudy of the Odyssey trial provided supportive data for this strategy in adolescents receiving Rif and DTG $50 \mathrm{mg}$ tablets. ${ }^{15}$ There is a lack of data on the pharmacokinetics of Rif and DTG DT; however, based on the data from adults and adolescents, the USFDA in the registration of DTG DT recommended twice-daily dosing of DTG DT in children receiving Rif. Further studies are required to confirm this strategy; however, international guidelines are likely to support this approach while awaiting more supporting data.

As other global medicine regulatory authorities have extensively reviewed the formulation, advocates for the right of children to have access to the best available treatment options, clinician groups and community organisations need to be more vocal in demanding that the approval of this formulation be expedited in South Africa.

\section{Future innovations for simplified paediatric-friendly formulations}

Further simplification of both treatment and prophylactic regimens for children in the future is likely to positively impact the goal of eliminating mother-to-child transmission and achieving the 95-95-95 milestone.

The recent registration of long-acting injectable cabotegravir/ rilpivirine (LA CAB/RPV) administered every 2 months in HIV-infected individuals over 18 years by the USFDA highlights the direction of future treatment simplification. Results from the Mocha trial will support the registration of LA CAB/RPV in adolescents between 12 and 18 years old. While the need for refrigeration during storage of LA CAB/RPV may limit the use in LMICs, it opens up new treatment options. This is because $\mathrm{LACAB} / \mathrm{RPV}$ is administered intramuscularly, where it forms a crystalline structure that slowly releases the active drug into the plasma. A planned study in protocol development (IMPAACT 2036) hopes to explore LA CAB/RPV in younger children 2-12 years of age and aims to start in 2022. As we move these formulations into younger patients, the injection volumes, injection site (gluteal vs lateral thigh), changes in weight between injections and changes in the absorption and metabolism will need further evaluation.

Other formulations and delivery mechanisms in development include long-acting oral and implantable formulations (e.g. islatravir and lenacapavir), long-acting broadly neutralising antibodies and microarray patches. Each of these formulations is likely to play a significant part in the future treatment and prevention options for children and adolescents.

The scope for simplifying paediatric ART regimens has vastly improved, with the potential for a once-a-day solid formulation regimen from 4 weeks of age. Robust advocacy from clinicians and the community is required to ensure that these life-changing formulations are made available to our patients as soon as possible.

\section{Acknowledgements}

The authors acknowledge Leora Sewnarain for formatting, language editing and proofreading the article. 


\section{Competing interests}

The authors declare that they have no financial or personal relationships that may have inappropriately influenced them in writing this article.

\section{Authors' contributions}

M.A., R.v.Z., N.S. and G.S. read and approved the final manuscript.

\section{Ethical considerations}

This article followed all ethical standards for research without direct contact with human or animal subjects.

\section{Funding information}

This research received no specific grant from any funding agency in the public, commercial or not-for-profit sectors.

\section{Data availability}

Data sharing is not applicable to this article as no new data were created or analysed in this study.

\section{Disclaimer}

The views and opinions expressed in this article are those of the authors and do not necessarily reflect the official policy or position of any affiliated agency of the authors.

\section{References}

1. Joint United Nations Programme on HIV/AIDS (UNAIDS). UNAIDS Data 2020 [homepage on the Internet]. [cited 2021 June 17]. Available from: https://www. unaids.org/en/resources/documents/2020/unaids-data

2. Woldesenbet SA, Jackson DJ, Lombard CJ, et al. Structural level differences in the mother-to-child HIV transmission rate in South Africa: A multilevel assessment of individual-, health facility-, and provincial-level predictors of infant HIV transmission. J Acquir Immune Defic Syndr. 2017;74(5):523-530. https://doi. org/10.1097/QAl.0000000000001289
3. Dorward J, Khubone T, Gate K, et al. The impact of the COVID-19 lockdown on HIV care in 65 South African primary care clinics: An interrupted time series analysis. Lancet HIV. 2021;8(3):e158-e165. https://doi.org/10.1016/S2352-3018(20) Lancet $30359-3$

4. Jewell BL, Mudimu E, Stover J, et al. HIV modelling consortium: Potential effects of disruption to HIV programmes in sub-Saharan Africa caused by COVID-19: Results from multiple mathematical models. Lancet HIV. 2020;7(9):e629-e640. https:// foi.org/10.1016/S2352-3018(20)30211-3

5. FDA Approved Drugs. ABACAVIR Sulfate and Lamivudine No. 202381 [homepage on the Internet]. [cited 2021 June 17]. Available from: https://www.accessdata. fda.gov/drugsatfda_docs/pepfar/202381PI.pdf

6. Access to Medicine Foundation. Ending the burden of HIV, malaria and TB in children: Children and the 'big three' epidemics: Despite significant advances in HIV, many children remain at risk, June 2020 [homepage on the Internet]. [cited 2021 June 17]. Available from: https://accesstomedicinefoundation.org/ publications/ending-the-burden-of-hiv-malaria-and-tb-in-children

7. Republic of South Africa Department of Health. Antiretroviral drug dosing chart for children 2021 [homepage on the Internet]. [cited 2021 June 21]. Available from: https://sahivsoc.org/Files/PaedDosingChart 2021.pdf

8. Republic of South Africa Department of Health. ART clinical guidelines for the management of HIV in adults, pregnancy, adolescents, children, infants and neonates [homepage on the Internet]. 2019 Oct [updated 2020 Mar; cited 2021 June 17]. Available from: https://www.knowledgehub.org.za/system/ files/elibdownloads/2020-05/2019\%20ART\%20Guideline $\% 2028042020 \% 20$ pdf.pdf

9. Viani RM, Alvero C, Fenton T, et al. P1093 study team: Safety, pharmacokinetics and efficacy of dolutegravir in treatment-experienced HIV-1 infected adolescents: Forty-eight-week results from IMPAACT P1093. Pediatr Infect Dis J. 2015;34(11):1207-1213. https://doi.org/10.1097/INF.0000000000000848

10. Viani RM, Ruel T, Alvero C, et al. P1093 study team: Long-term safety and efficacy of dolutegravir in treatment-experienced adolescents with human immunodeficiency virus infection: Results of the IMPAACT P1093 study. J Pediatric Infect Dis Soc. 2020;9(2):159-165. https://doi.org/10.1093/jpids/piy139

11. Bollen PDJ, Moore CL, Mujuru HA, et al. ODYSSEY trial team: Simplified dolutegravir dosing for children with HIV weighing $20 \mathrm{~kg}$ or more: Pharmacokinetic and safety substudies of the multicentre, randomised ODYSSEY trial. Lancet HIV. 2020;7(8):e533-e544. https://doi.org/10.1016/S2352-3018(20)30189-2

12. International Maternal Pediatric Adolescent AIDS Clinical Trials Network (IMPAACT). P1093 abstracts [homepage on the Internet]. [cited 2021 June 17]. Available from: https://www.impaactnetwork.org/publications/abstracts?search api_fulltext=P1093

13. Medicines Patent Pool. Dolutegravir - Paediatrics (DTG) [homepage on the Internet]. ViiV Healthcare, April 2014. [cited 2021 June 17]. Available from https://medicinespatentpool.org/licence-post/dolutegravir-paediatrics-dtg/

14. Turkova A. Dolutegravir-based ART is superior to NNRTI/PI-based ART in children and adolescents [homepage on the Internet]. 28th conference on retroviruse and opportunistic infections (CROI). Abstract No. 174; June 3 - Nov 3, 2021 Virtual [cited 2021 June 17]. Available from: https://www.croiconference.org/ abstract/dolutegravir-based-art-is-superior-to-nnrti-pi-based-art-in-children-andadolescents/

15. Waalewijn H, Mujuru HA, Amuge P, et al. Adequate dolutegravir exposure dosed BID with rifampicin in children 6 to $<18$ years [homepage on the Internet]. 27th conference on retroviruses and opportunistic infections (CROI). Abstract No. 847 Mar 8-11, 2020. Boston, MA. [cited 2021 June 17]. Available from: https://www. croiconference.org/abstract/adequate-dolutegravir-exposure-dosed-bid-withrifampicin-in-children-6-to/ 